\title{
PENGARUH JALAN SANTAI TERHADAP KADAR GLUKOSA DARAH SEWAKTU PADA PENDERITA DIABETES MELLITUS DI PUSKESMAS KARANG TALIWANG MATARAM NUSA TENGGARA BARAT TAHUN 2019
}

\author{
Fahrunnisa*, Ety Retno Setyowati**, Nyoman Cahyadi*** \\ FakutasKedokteranUniversitas Islam Al-Azhar \\ Jl. Unizar No. 20 TuridaMataram
}

\begin{abstract}
ABSTRAK
Latar belakang : Diabetes mellitus merupakan penyebab utama kematian disebagian besar negara maju. Pengelolaan penyakit diabetes mellitus dikenal dengan empat pilar utama yaitu penyuluhan atau edukasi, terapi gizi medis, latihan jasmani dan intervensi farmakologis. Berjalan kaki merupakan salah satu bentuk latihan jasmani yang direkomendasikan untuk dilakukan sehari-hari bagi penderita diabetes.

Tujuan penelitian : Untuk mengetahui apakah ada pengaruh jalan santai terhadap kadar glukosa darah sewaktu pada penderita diabetes mellitus di Puskesmas Karang Taliwang Mataram Nusa Tenggara Barat Tahun 2019.

Metode penelitian : Penelitian ini menggunakan metode pre-eksperimental. Sedangkan desain atau rancangan penelitian ini adalah one group pretest-posttest. Jumlah sampel sebesar 30 responden yang diambil dengan menggunakan tekhnik purposive sampling.

Hasil penelitian : Hasil pretest dan posttest data menunjukan bahwa, rerata kadar glukosa darah sewaktu pada penderita diabetes mellitus di Puskesmas Karang Taliwang Mataram Nusa Tenggara Barat Tahun 2019 sebelum jalan santai sebesar 194,17 mg/dL. Sedangkan rerata kadar glukosa darah sewaktu pada penderita diabetes mellitus di Puskesmas Karang Taliwang Mataram Nusa Tenggara Barat Tahun 2019 sesudah jalan santai sebesar 182,7 mg/dL. Hal ini diperkuat oleh hasil uji statistik (uji t) menunjukkan bahwa nilai $\mathrm{p}=0.04$ artinya $p$ value $<0.05$, artinya terdapat pengaruh yang signifikan antara jalan santai terhadap kadar glukosa darah pada penderita diabetes mellitus di Puskesmas Karang Taliwang Mataram Nusa Tenggara Barat Tahun 2019.
\end{abstract}

Kata Kunci : Diabetes Mellitus, Jalan Santai, Kadar Glukosa Darah.

\section{PENDAHULUAN}

Diabetes merupakan penyebab utama kematian di sebagian besar negara maju. Menurut International Diabetes Federation (IDF) tahun 2012, lebih dari 371 juta orang di seluruh dunia mengalami Diabetes Melitusdan 4,8 juta orang meninggal akibat penyakit metabolik ini (Badan Penelitian dan Pengembangan Kesehatan, 2013). Pada tahun 2003 WHO memperkirakan 194 juta jiwa atau 5,1 \% dari 3,8 miliar penduduk dunia yang berusia 20-79 tahun menderita Diabetes Melitusdan pada 2025 akan meningkat menjadi 333 juta jiwa.
WHO memprediksi Indonesia, bahwa ada kenaikan dari 8,2 juta diabetesi pada tahun 2000, akan meningkat menjadi sekitar 21,3 juta diabetesi pada tahun 2030. Hal ini akan menjadikan Indonesia menduduki rangking ke 4 (empat) dunia setelah Amerika Serikat, China, dan India dalam prevalensi diabetes (Departemen Kesehatan Republik Indonesia, 2008).

Diabetes mellitus merupakan penyakit kronis yang terjadi saat pankreas tidak dapat memproduksi insulin secara cukup atau saat tubuh tidak dapat secara efektif menggunakan insulin yang dihasilkan sehingga menyebabkan 
peningkatan konsentrasi glukosa dalam darah (hiperglikemia) (WHO, 2012). Hiperglikemia dalam jangka panjang dapat menimbulkan komplikasi mikrovaskular (retinopati, nefropati, neuropati) dan komplikasi makrovaskular (aterosklerotik, stroke, angina, infark miokardium, gangren) (Price \& Wilson, 2005).

Menurut Meita dalam bukunya Silent Killer Desease mengatakan cara untuk menurunkan kadar gula darah, yaitu dengan melakukan aktivitas fisik, seperti berolahraga karena otot menggunakan glukosa dalam darah untuk menghasilkan energi (Shanti, 2011). Olahraga mengurangi resistensi insulin sehingga kerja insulin lebih baik dan mempercepat pengangkutan glukosa masuk ke dalam sel untuk kebutuhan energi. Makin banyak olahraga, makin cepat dan makin banyak glukosa yang dipakai (Tandra, 2007).

Jalan kaki merupakan cara mudah dan murah untuk sehat, namun untuk memperoleh hasil maksimal bagi kesehatan perlu diperhatikan posisi kaki saat berjalan (Kurniali \& Brotoasmoro, 2007). Menurut American College of Sports Medicine (ACSM) aktivitas berjalan kaki merupakan bentuk aktivitas fisik yang direkomendasikan untuk dilakukan sehari-hari. Jalan kaki yang dilakukan dalam frekuensi tertentu bahkan dapat menurunkan resiko terkena penyakit metabolik seperti
Diabetes Mellitus (kencing manis), kolesterol tinggi (dislipidemia), hipertensi dan penyakit jantung koroner (Hage, 2013).

Hal ini dibuktikan dari hasil penelitian yang dilakukan Fauzi (2013) jalan kaki dengan intensitas sedang dan tinggi dapat menurunkan glukosa darah karena dapat meningkatkan ambilan glukosa oleh otot dibandingkan dengan pelapasan glukosa hepar selama kegiatan.

Penelitian lain yang dilakukan oleh colberg, et al (2013) bertujuan untuk mengetahui respon glukosa darah terhadap tipe latihan, intensitas latihan, dan waktu latihan yang berbeda. Tipe latihan yang digunakan dalam penelitian adalah berjalan, berlari, bersepeda, dan menari dengan intensitas sedang atau tinggi selama 10-30 menit, dan waktu latihan 30 menit. Hasil dari penelitian, latihan-latihan tersebut dapat menurunkan kadar glukosa darah mg/dL ,untuk berjalan $25,0 \mathrm{mg} / \mathrm{dL}$, berlari $40,1 \mathrm{mg} / \mathrm{dL}$, bersepeda $42,4 \mathrm{mg} / \mathrm{dL}$, dan menari 37,4 $\mathrm{mg} / \mathrm{dL}$. Latihan intensitas sedang menurunkan hingga $32,7 \mathrm{mg} / \mathrm{dL}$, sedangkan intensitas tinggi hanya menurunkan 28,0 mg/dL.

Berdasarkan latar belakang diatas, dan belum adanya penelitian tentang pengaruh jalan santai terhadap kadar glukosa darah sewaktu pada penderita Diabetes Mellitus di NTB, maka penulis ingin melakukan penelitian untuk mengetahui pengaruh jalan santai 
terhadap kadar glukosa darah pada penderita Diabetes Mellitus di Puskesmas Karang Taliwang Mataram NTB Tahun 2019.

\section{BAHAN DAN METODE}

Jenis penelitian yang digunakan pada penelitian ini adalah preeksperimental dengan rancangan one group pretest-posttest. One group pretestposttest adalah rancangan yang tidak ada kelompok pembanding (kontrol) namun sudah dilakukan observasi pertama (pretest) yang memungkinkan peneliti dapat menguji perubahan yang terjadi setelah adanya ekperimen (posttest) (Notoatmodjo, 2005).

Perlakuan yang diberikan berupa jalan santai dan pengukuran $\left(\mathrm{O}_{1}\right.$ dan $\left.\mathrm{O}_{2}\right)$ yang dilakukan adalah kadar glukosa darah pasien Diabetes Melitus di Puskesmas Karang Taliwang Mataram. Alasan peneliti memilih jenis penelitian ini adalah untuk mengetahui pengaruh jalan santai terhadap kadar glukosa darah pasien Diabetes melitus tanpa membandingkan dengan variabel kontrol. Untuk menentukan bahwa hasil posstest yang diperoleh pada akhir penelitian merupakan akibat dari intervensi, maka peneliti membatasi karakteristik responden dengan beberapa criteria. Rancangan penelitian dapat digambarkan dalam bagan berikut:

\section{Pretest Perlakuan Posttest}

$$
\begin{array}{lll}
\mathrm{O}_{1} & \mathrm{X} & \mathrm{O}_{2}
\end{array}
$$

Keterangan :

$$
\begin{array}{lll}
\mathrm{O}_{1} & =\text { Pretest } & \text { (pemeriksaan } \\
& \text { kadarglukosa darah sebelum } \\
& \text { jalan santai). } \\
\mathrm{X} & =\text { Perlakuan (jalan santai } 20 \\
& \text { menit). } \\
\mathrm{O}_{2} & =\text { Posttest (pemeriksaan kadar } \\
& \text { glukosa darah setelah jalan } \\
& \text { santai). }
\end{array}
$$

Penelitian dilakukan di Puskesmas Karang Taliwang Kota Mataram, Provinsi Nusa Tenggara Barat. Populasi dalam penelitian ini adalah seluruh pasien Diabetes Melitus Puskesmas Karang Taliwang Kota Mataram tahun 2019. Sampel yang digunakan adalah pasien yang mengikuti jalan santai di perkumpulan pasien Diabetes Melitus Puskesmas Karang Taliwang Kota Mataram tahun 2019 yang sesuai dengan kriteria inklusi sebanyak 30 dengan tekhnik purposive sampling orang berdasarkan rumus :

$$
\mathrm{n}=\left|\frac{(\mathrm{Z} \alpha+\mathrm{Z} \beta) \mathrm{Sd}}{\mathrm{d}}\right|^{2}
$$

$\mathrm{Z} \alpha=$ kesalahan tipe 1 ditetapkan 5\%, jadi deviat baku $\alpha=1,960$ $\mathrm{Z} \beta=$ kesalahan tipe 2 ditetapkan $20 \%$, jadi deviat baku $\beta=0.842$

$\mathrm{Sd}=$ standar deviasi gabungan $=28$

$\mathrm{d}=$ selisih minimal rerata yang dianggap bermakna $=15$

Maka : 


$$
\begin{aligned}
\mathrm{n}= & \left|\frac{(\mathrm{Z} \alpha+\mathrm{Z} \beta) \mathrm{Sd}}{\mathrm{d}}\right|^{2} \\
\mathrm{n} & =\left|\frac{(1,96+0,842) 28}{15}\right|^{2} \\
\mathrm{n} & =\left|\frac{78,456}{15}\right|^{2} \\
\mathrm{n} & =|5,23|^{2} \\
\mathrm{n} & =27,35+10 \% \\
\mathrm{n} & =30
\end{aligned}
$$

Kriteria inklusi :

1) Responden pasien penderita Diabetes Mellitus.

2) Responden yang bersedia mengikuti penelitian.

Kriteria eksklusi :

1) Responden yang melakukan

aktivitas fisik berat sebelum penelitian.

2) Responden menderita penyakit hepar.

3) Responden memiliki riwayat peminum alkohol.

4) Responden minum kopi dan minum teh sebelum penelitian.

5) Responden minum obat penurun kadar glukosa darah sebelum penelitian.

Instrumen penelitian metode pengamatan kadar glukosa darah menggunakan alat Easy Touch.

Glukometer Easy Touch adalah alat yang dapat mengukur gula dalam darah dalam $\mathrm{mg} / \mathrm{dL}$. Selanjutnya pengumpulan data dilakukan sebelum dan sesudah jalan santai pada pasien Diabetes Melitus. Alur pengambilan data adalah sebagai berikut :

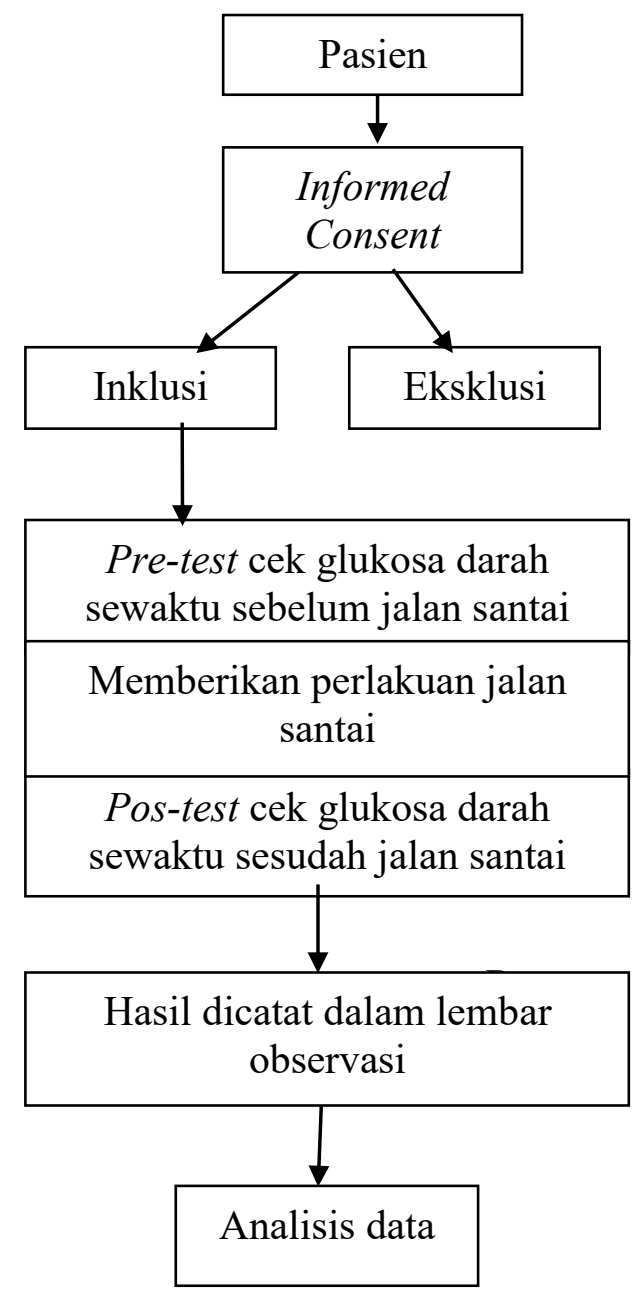

Data yang telah terkumpul akan diolah dan dianalisis dengan bantuan komputer menggunakan program SPSS (Statistical Package for the Social Sciences).

Uji statistik yang digunakan dalam penelitian ini adalah uji Non-Parametrik ( uji Wilcoxon) karena uji statistik ini tidak memerlukan asumsi kenormalan data.

\section{HASIL PENELITIAN}

Hasil menunjukan karakteristik dasar sampel berdasarkan usia responden dari total 30 sampel responden penelitian didapatkan yang berusia antara 43-55 tahun 8 responden $(26,7 \%)$ dan berusia 
antara 56-65 tahun 11 responden $(36,7 \%)$ serta yang berumur lebih dari 65 tahun sebanyak 11 responden $(36,7 \%)$. Usia termuda pada sampel penelitian ini adalah 43 tahun sedangkan usia tertua pada sampel penelitian ini adalah 77 tahun. Dari total 30 sampel responden penelitian didapatkan 9 responden berjenis kelamin laki-laki (30,0\%) dan 21 responden berjenis kelamin perempuan $(70,0 \%)$.

Tabel 1.1 Karakteristik kadar glukosa darah sewaktu berdasarkan WHO (2012).

\begin{tabular}{|c|c|c|c|c|c|}
\hline \multirow{2}{*}{$\begin{array}{c}\text { Kadar Glukosa } \\
\text { Darah }\end{array}$} & \multicolumn{4}{|c|}{ Kategori } & \multirow{2}{*}{$\rho$-value } \\
\hline & Baik(96-144) & Sedang(145-179) & Buruk(>180) & & \\
\hline \multirow[t]{2}{*}{ Sebelum } & $9(30,0 \%)$ & $4(13,3 \%)$ & $17(56,7 \%)$ & & \\
\hline & & & & 0,001 & \\
\hline Sesudah & $11(36,7 \%)$ & $6(20,0 \%)$ & $13(43,3 \%)$ & & \\
\hline
\end{tabular}

Tabel 1.2 Perubahan Kadar Glukosa Darah

\section{No \\ Perubahan Kadar Glukosa Darah Sesudah Jumlah Responden \\ Jalan Santai}

\begin{tabular}{lcc}
\hline \hline 1 & Meningkat & 4 Responden \\
2 & Menurun & 26 Responden \\
& \\
\hline \hline
\end{tabular}

Tabel 1.3 Rerata Kadar Glukosa Darah Sebelum Dan Sesudah Jalan Santai

\begin{tabular}{|l|r|r|r|r|}
\hline & \multicolumn{1}{|c|}{$\mathrm{N}$} & \multicolumn{1}{|c|}{ Minimum } & Maximum & \multicolumn{1}{c|}{ Mean } \\
\cline { 2 - 6 } & \multicolumn{1}{|c|}{ Statistic } & Statistic & \multicolumn{1}{c|}{ Statistic } & Statistic \\
\hline Sebelum Jalan Santai & 30 & 96.00 & 344.00 & 194.1667 \\
Sesudah Jalan Santai & 30 & 97.00 & 369.00 & 182.5667 \\
Valid N (listwise) & 30 & & & \\
\hline
\end{tabular}

Wilcoxon Signed Ranks Test

\begin{tabular}{|ll|r|r|r|}
\hline & N & Mean Rank & Sum of Ranks \\
\hline & Negative Ranks & $25^{\mathrm{a}}$ & 15.66 & 391.50 \\
Sebelum - & Positive Ranks & $5^{\mathrm{b}}$ & 14.70 & 73.50 \\
Sesudah & Ties & $0^{\mathrm{c}}$ & & \\
& Total & 30 & & \\
\hline
\end{tabular}


Tabel 1.4 Uji Statistik Wilcoxon

Test Statistics $^{\mathrm{a}}$

\begin{tabular}{|l|r|}
\hline & \multicolumn{2}{|c|}{ Sebelum - Sesudah } \\
\hline$Z$ & $-3.273^{\mathrm{b}}$ \\
Asymp. Sig. (2-tailed) & .001 \\
\hline
\end{tabular}

Berdasarkan hasil perhitungan yang menggunakan uji non-parametrik (uji Wilcoxon), diperoleh hasil nilai p sebesar 0,001 . Hasil ini menunjukkan pada penelitian ini terdapat pengaruh yang signifikan antara jalan santai terhadap kadar glukosa darah sewaktu penderita diabetes mellitus di Puskesmas Karang Taliwang Mataram Nusa Tenggara Barat 2019. Pada penelitian ini menunjukkan bahwa responden perempuan lebih banyak dari pada laki-laki yaitu responden laki-laki sebanyak 9 orang dan responden perempuan sebanyak 21 orang, hal ini dikarenakan Proporsi yang mengikuti jalan santai lebih banyak perempuan dibandingkan laki-laki selain itu wanita cenderung memiliki aktifitas yang lebih ringan dibandingkan laki-laki serta gaya hidup dan ketidakseimbangan pola makan sehingga wanita lebih beresiko terkena diabetes mellitus (Tandra, 2007). Hasil penelitian menunjukkan bahwa 26 subyek penelitian menunjukkan hasil yang signifikan artinya terjadi penurunan kadar glukosa darah sewaktu yaitu $0,001 \quad(\mathrm{p}<0,05)$ sesudah melakukan jalan santai hal ini dikarenakan saat melakukan aktivitas fisik, salah satunya seperti jalan santai, dapat menyebabkan glukosa di dalam tubuh digunakan melalui kerja hormon insulin oleh karena peningkatan sensitivitas reseptor insulin pada otot selama berolahraga untuk menghasilkan energi. Hal ini akan mengakibatkan menurunnya glukosa darah sehingga memperbesar pengendalian glukosa darah (Barnes, 2012). Hasil penelitian ini sesuai dengan penelitian Subroto (2006) yang menyatakan bahwa diabetesi dapat berolah raga seperti jalan kaki untuk menekan kadar gulanya. Pada diabetes melitus tipe 2 olah raga sangat berkaitan dengan pengontrolan kadar gula darah diabetesi. Olah raga secara teratur dapat mengurangi resistensi insulin sehingga insulin dapat digunakan dengan lebih baik oleh sel-sel tubuh dan dosisnya dapat diturunkan. Hasil penelitian ini menunjukkan bahwa 4 subyek penelitian menunjukkan hasil yang tidak signifikan artinya terjadi peningkatan kadar glukosa darah sewaktu sesudah melakukan jalan santai pada pendertia diabetes mellitus di Puskesmas Karang Taliwang Mataram Nusa Tenggara Barat tahun 2019 dapat 
disebabkan sesudah melakukan jalan santai bisa saja responden melakukan sesuatu yang tidak terlihat oleh peneliti seperti : makan atau minum obat yang memicu pada kenaikan kadar glukosa darah sewaktu atau minum teh atau minum kopi, sehingga ketika melakukan pemeriksaan kadar glukosa darah sewaktu setelah jalan santai, kadar glukosa darah sewaktu pada responden tersebut meningkat dibandingkan dengan kadar glukosa darah sewaktu sebelum melakukan jalan (Tandra, 2007). Selain itu bisa juga karena responden mengalami dehidrasi setelah melakukan jalan santai, kekurangan cairan atau dehidrasi juga dapat meningkatkan kadar glukosa darah, karena glukosa yang bersikulasi menjadi lebih terkonsentrasi (Toruan, 2014). Penelitian ini sesuai dengan penelitian yang telah dilakukan oleh Santoso (2008) yang menyatakan bahwa porsi latihan olah raga bagi diabetesi hendaknya harus memperhatikan intensitas latihan, lama latihan dan frekuensi latihan. Untuk mencapai kesegaran kardiovaskular yang optimal maka idealnya latihan berada pada V02 max, berkisar antara $50-85 \%$ ternyata tidak memperburuk komplikasi diabetes melitus.

\section{SIMPULAN}

Berdasarkan hasil dan pembahasan mengenai pengaruh jalan santai terhadap kadar glukosa darah sewaktu pada penderita DM di Puskesmas Karang Taliwang Mataram Nusa Tenggara Barat Tahun 2019, dapat di tarik kesimpulan sebagai berikut: Penelitian ini telah mengidentifikasi beberapa karakteristik dari 30 responden. Usia responden dari 43 tahun sampai 77 tahun dengan kelompok usia lansia awal (43-55 tahun) sebanyak 8 responden atau sebanyak 26,7\%, lansia akhir (56-65 tahun) sebanyak 11 responden atau sebanyak 36,7\%, sedangkan manula ( $>180$ tahun) sebanyak 11 responden atau sebanyak 36,7\%. Responden terdiri dari 9 laki-laki (30,0\%) dan 21 perempuan (70\%). Rerata kadar glukosa darah sewaktu pada penderita DM di Puskesmas Karang Taliwang Mataram Nusa Tenggara Barat Tahun 2019 sebelum melakukan jalan santai sebesar 194,17 mg/dL. Rerata kadar glukosa darah sewaktu pada penderita DM di Puskesmas Karang Taliwang Mataram Nusa Tenggara Barat Tahun 2019 sesudah melakukan jalan santai sebesar 182,57 mg/dL.

Terdapat pengaruh yang signifikan antara jalan santai terhadap kadar glukosa darah pada penderita DM di Puskesmas Karang Taliwang Mataram Nusa Tenggara Barat Tahun 2019.

\section{SARAN}

Bagi Penderita Diabetes Mellitus dianjurkan melakukan olahraga secara teratur setiap harinya, karena dengan olahraga secara teratur, contohnya seperti 
jalan santai 20 menit ternyata dapat membantu menurunkan kadar glukosa darah sewaktu.

Bagi Peneliti lain yang mana penelitian ini dapat digunakan sebagai sumber informasi bagi peneliti yang akan melakukan penelitian yang lebih lanjut.

\section{DAFTAR PUSTAKA}

Ahmad et al. 2015. Evaluation of reliability and validity of the general practice physical activity questionnaire (GPPAQ) in 60-74 year old primary care patients. BMC Family Practice, 16(113), 19.

Allorerungm Desy L., Sekeon, Sekplin A.S., Joseph, Wooford B.S. 2016. Hubungan antara Umur, Jenis Kelamin dan tingkat pendidikan dengan Kejadian Diabetes Mellitus Tipe 2 di Puskesmas Ranotana Weru Kota Manado 2016. Diakses pada 22 januari 2019 dari http://scholar.google.co.id.

American Diabetes Association. Standards of Medical Care in Diabetes . 2015. Diabetes Care ;38 (Sppl 1):S1-S87.

Arikunto, Suharsimi. 2010. Prosedur Penelitian: Suatu Pendekatan Praktik. Jakarta: Rineka Cipta.

Badan Penelitian dan Pengembangan Kesehatan. 2013. Riset Kesehatan Dasar 2013. Jakarta.

Barnes, D.E. 2011.Program Olahraga Diabetes. Yogyakarta : Citra Aji Parama.

Blackburn, JA., Dulmus CN. 2007. Handbook of Gerontology Evidence Based Approaches to Theory, Practice, and Policy.

Colberg, Sheri.,Sigal, Ronald. 2013. Exercise and Type 2 Diabetes. Diabetes Care.Vol.33, No. 12.
Corwin, EJ. 2009. Buku Saku Patofisiologi, 3 Edisi Revisi. Jakarta: EGC

D'Agostino. R. B. 1986. Tests for Normal Distribution in Goodness-Of-Fit Techniques. R.B. D'Agostino and MA Stephens (ed), Marcel Dekker

Departemen Kesehatan RI. 2008. Pedoman Pengendalian Diabetes Melitus dan Penyakit Metabolik. Jakarta.

Departemen Kesehatan RI. 2009. Sistem Kesehatan Nasional. Jakarta.

Dorland , 2010. Kamus Kedokteran. Jakarta : EGC.

Dustine, JR. 2012. Program Olahraga Kolesterol Tinggi: Panduan Untuk Mencegah Peningkatan Kolesterol dan Mempertahankan Kesehatan Jantung. Yogyakarta: PT Citra Aji Pramana.

Fauzi, L. 2013. Intensitas Jalan Kaki terhadap Penurunan Kadar Glukosan Darah.Kemas.8.2 : 2013 : 106-112.

Fauzi. L., Anggorowati . L. 2013. Perbedaan Intensitas Jalan Kaki dengan Terhadap Penurunan Kadar Glukosa Darah . J Kes Mas. 8(2):85-91.

Gustaviani. 2006. Diagnosis dan Klasifikasi Diabetes Melitus. In: Aru WS, Bambang S, Idrus A, Marcellus SK, Siti S, editors. Buku ajar ilmu penyakit dalam jilid III edisi IV.Jakarta : Pusat Penerbitan Departemen Ilmu Penyakit Dalam FKUI. p. 1857-1859.

Guyton, A. C., \& Hall, J. E.. 2007. Buku Ajar Fisiologi Kedokteran. Jakarta: EGC.

Guyton, A. C., \& Hall, J. E.. 2012. Buku Ajar Fisiologi Kedokteran. Edisi 6. Jakarta: EGC.

Horden, M. D., et.al. (2012). A position statement from Exercise and Sport Science Australia. Journal of 
Science and Medicine in Sport, 15, pp. 25-31.

International Diabetes Federation. 2007. Panduan Untuk Manajemen Glukosa Pasca-Makan.

Irawan, M. Anwari. 2007. Glukosa dan Metabolisme Energi. http://www.pssplab.com/journal/06 .pdf. Diakses pada 30 April 2018.

Kurniali \& Brotoasmoro. 2007. Move Your Body Right. Jakarta : PT. Elex Media Komputindo.

Lee, Joyce le Fever. 2007. Pedoman Pemeriksaan Laboratorium \& Diagnostic. Joyce le Fever Kee : alih bahasa, Sari Kurnianingsih (et al); editor edisi Bahasa Indonesia, Ramona P. Kapoh-Ed.6.Jakarta : EGC.

Misnadiarly. 2006. Diabetes Mellitus: Gangren, Ulcer, Infeksi. Mengenal gejala, Menanggulangi, dan Mencegah Komplikasi. Jakarta: Pustaka Populer Obor.

Murray, Robert K. 2009. Biokimia Harper edisi 27.Jakarta : EGC.

Nurmalina, Rina. 2011. Pencegahan \& Manajemen Obesitas. Bandung : Elex Media Komputindo.

Notoatmodjo, S. 2010. Metodologi Penelitian Kesehatan, Edisi Revisi. Jakarta: Rineka Cipta.

Notoatmodjo, S. 2010. Metodologi Penelitian Kesehatan. Jakarta: PT. Rineka Cipta.

Palar, C.M. Wongkar, D. dan Ticoalu, S.H.R. 2015. Manfaat Latihan Olahraga Aerobik Terhadap Kebugaran Fisik Manusia. Skripsi. Manado: Universitas Sam Ratulangi Manado.

PERKENI. 2006. Konsensus Pengelolaan Diabetes Mellitus di Indonesia. Jakarta :Perkumpulan Endokrinologi Indonesia.

PERKENI.2015. Konsesus Pengelolaan dan Pencegahan Diabetes Mellitus Tipe 2 di Indonesia.Jakarta
:Pengurus Besar Perkumpulan Endokrinologi Indonesia.

Price, Sylvia \& Wilson, Lorraine. 2005. Patofisiologi: Konsep Klinis Proses-Proses Penyakit. Edisi 6. Jakarta: EGC.

Rab, T. 2008. Agenda Gawat Darurat (Critical Care). Bandung: Penerbit PT Alumni.

Rondhianto. 2011. Pengaruh Diabetes Self Management Education Dalam Discharge Planning Terhadap Self Efficacy dan Self Care Behavior Pasien Diabetes Mellitus Tipe 2. Surabaya: UniversitasAirlangga.

Santoso. 2008. Senam Diabetes . Jakarta : Persadia.

Shanti, Meita. 2011. Silent Killer Deseases. Jogjakarta: Javalitera.

Subroto. 2006. VCO Dosis Tepat Takhlukkan Penyakit. Jakarta : PT Puspa Swara.

Sudoyo, A.W., et al. 2006. Buku Ajar Penyakit Dalam, Jilid III. Edisi 4. Jakarta: Fakultas Kedokteran Universitas Indonesia.

Sukandar, Elin Yulianah dkk. 2008. Iso Farmako Terapi. Jakarta : PT.ISFI.

Sustrani, L., et al. 2006. Diabetes. Jakarta: Gramedia Pustaka Utama.

Suyono, Slamet. 2007. Diabetes Melitus di Indonesia. Ilmu Penyakit Dalam. Jakarta: Pusat Penerbitan Ilmu Penyakit Dalam FKUI.

Suyono, Slamet. 2009. Kecenderungan Peningkatan Jumlah Penyandang Diabetes.Dalam Soegondo et al. Penatalaksanaan Diabetes Mellitus Terpadu. Edisi Kedua. Jakarta: Balai Penerbit FKUI.

Tandra, Hans. 2007. Segala Sesuatu yang Harus Anda Ketahui Tentang Diabetes. Jakarta: Pt. Gramedia Pustaka Utama.

The Global Diabetes Community. 2014. Type 2 Diabetes. Diabetes.co.uk.Retrivied April, 30, 
2018, from http :/www.diabetes.co.uk/type2diabetes.html.

Toruan. 2014. Weight Loss : Kiat Langsing Seumur Hidup. Jakarta :Transmedia Pustaka.

Fakultas Kedokteran Universitas Indonesia.

World Health Organization. 2012. Diabetes.

http://www.who.int/topics/diabetes mellitus/en/. [30 April 2018].

Waspadji, S. 2011. Diabetes Melitus: Mekanisme dan Dasar Pengelolaannya yang Rasional dalam: Soegondo, S., Soewondo, P., Subekti, I., Editor.Penatalaksanaan Diabetes Melitus Terpadu bagi dokter maupun edukator diabetes. Jakarta: 